\title{
Bmal1 suppresses cancer cell invasion by blocking the phosphoinositide 3-kinase-Akt-MMP-2 signaling pathway
}

\author{
CHAN-HUN JUNG ${ }^{1}$, EUN MI KIM ${ }^{1}$, JONG KUK PARK $^{1}$, SANG-GU HWANG $^{1}$, \\ SUNG-KWON MOON ${ }^{2}$, WUN-JAE KIM ${ }^{3}$ and HONG-DUCK UM ${ }^{1}$
}

\author{
${ }^{1}$ Division of Radiation Cancer Biology, Korea Institute of Radiological and Medical Sciences, Seoul 139-706; \\ ${ }^{2}$ Department of Biotechnology, Chungju National University, Chungju, Chungbuk; ${ }^{3}$ Department of Urology, \\ College of Medicine, Chungbuk National University, Cheongju, Chungbuk, Republic of Korea
}

Received November 29, 2012; Accepted February 5, 2013

DOI: $10.3892 /$ or.2013.2381

\begin{abstract}
Bmal1 is a core factor in the regulation of circadian rhythms. Previous studies have shown that Bmal1 suppresses tumor growth in cell culture and animal models and is downregulated in certain types of cancer. The aim of the present study was to investigated whether Bmall influences the invasiveness of cancer cells. We demonstrated that knockdown of Bmal1 by RNA interference promoted cancer cell invasion, whereas its overexpression reduced cellular invasiveness. These effects were observed in lung cancer and glioma cells, and occurred regardless of p53 status. Therefore, it appears that Bmal1 suppresses the invasion of multiple cancer types in a p53-independent manner. Bmal1 knockdown-induced cancer cell invasion was accompanied by activation of the PI3K-Akt-MMP-2 pathway, and was prevented by inhibitors of PI3K, Akt or MMP-2. This suggests that Bmal1 suppresses cell invasion by blocking the PI3K-Akt-MMP-2 pathway. Since this invasion pathway is activated by the oncogene Bcl-w, we investigated whether Bmall affects the activity of Bcl-w. As expected, Bmall attenuated the ability of Bcl-w to promote MMP-2 accumulation and cell invasion, supporting the idea that Bmall antagonizes Bcl-w activity. Collectively, our data suggest that Bmal1 is a tumor suppressor, capable of suppressing cancer cell growth and invasiveness, and support the recent proposal that there is a tight molecular link between circadian rhythms and tumor formation/progression.
\end{abstract}

\section{Introduction}

Metastasis of cancer cells is the most common reason for therapy failure. Although researchers have proposed a broad spectrum of mechanisms for cell migration and invasion,

Correspondence to: Dr Hong-Duck Um, Division of Radiation Cancer Biology, Korea Institute of Radiological and Medical Sciences, 215-4 Gongneung-dong, Nowon-gu, Seoul 139-706, Republic of Korea E-mail: hdum@kcch.re.kr

Key words: Bmall, cancer invasion, tumor suppressor, circadian clocks, Bcl-w cancer therapeutics designed to block tumor progression by modulating these mechanisms have not yet proven effective in clinical trials. This may reflect the fact that cancer cells can operate different migration programs under different environmental conditions (1). Therefore, comprehensive understanding of the molecular and cellular underpinnings of cancer cell migration/invasion to better understand cancer metastasis and support the development of new treatment strategies is needed.

Circadian clocks, which are the body's molecular timekeeping systems, form the basis for the daily rhythms of multiple biochemical, physiological and behavioral processes in most organisms $(2,3)$. Importantly, substantial evidence suggests that dysfunctions of the circadian system are associated with pathological conditions, such as the formation and progression of cancer. For example, an increased risk of breast cancer was reportedly associated with female workers who were exposed to chronic disruptions of the sleep-wake cycle, such as flight attendants and rotating or permanent nightshift workers (4-6). Numerous other epidemiological studies have shown that perturbation of the normal circadian rhythm increases the risk of not only breast cancer, but also prostate, colorectal and endometrial cancers (7).

In mammals, the circadian system is regulated by a set of core clock factors, including Bmal1, Clock, casein kinase I $\varepsilon$, the cryptochromes (Cry1 and 2) and the periods (Per13 ), as well as supplementary regulators such as $\operatorname{ROR} \alpha$ and REV-ERB $\alpha$ (8-10). Per1 and Per2 are relatively well characterized in terms of their roles in cancer. They are reportedly downregulated in various types of human cancer (11-14), and Per2 gene-deficient mice exhibit an increased rate of lymphoma formation in response to ionizing radiation (15). At the molecular level, Perl and Per2 are involved in the DNA damage response (16), and overexpression of either protein inhibits cancer cell growth and increases the apoptotic rate (16-18), supporting the notion that they participate in tumor suppression. Aside from these findings, however, there is little information regarding the molecular linkage between circadian rhythms and tumor formation/progression.

Bmal1 [brain and muscle aryl hydrocarbon receptor nuclear translocator (ARNT)-like] is a central clock factor that regulates the expression levels of the Cry and Per genes (19). 
Based on a recent report that downregulation of Bmall promotes tumor growth in cell culture and mice (20), we herein investigated whether Bmal1 also influences the invasiveness of cancer cells. The obtained data are presented in this study and the importance of our findings is discussed.

\section{Materials and methods}

Antibodies and inhibitors. Antibodies were purchased from the following institutions: anti-Bmall and anti-Akt from Santa Cruz Biotechnology (Santa Cruz, CA, USA); anti-phosphoinositide 3-kinase (PI3K) from Upstate Biotechnology (Lake Placid, NY, USA); anti-Bcl-w, anti-PTEN, and antiphospho-Akt from Cell Signaling Technology (Danvers, MA, USA); anti- $\beta$-actin from Sigma-Aldrich (St. Louis, MO, USA); and anti-MMP-2 from Calbiochem (La Jolla, CA, USA). The synthetic inhibitors were obtained from Calbiochem.

Cell culture, transfection and treatment. Human lung cancer cells (A549 and H1299) and glioma cells (U251) were cultured in RPMI-1640 and DMEM, respectively, supplemented with $10 \%$ heat-inactivated FBS. The Bmall-expressing pCMVSPORT6 vector (Thermo Fisher Scientific, Rockford, IL, USA), Bcl-w-expressing pcDNA3 vector (21), and siRNAs against Bmal1, Per3 and ROR $\alpha$ (Ambion, Austin, TX, USA) were introduced into cells using Lipofectamine 2000 (Invitrogen, Carlsbad, CA, USA) according to the manufacturer's protocol. All transfections were performed transiently, and transfectants were used for the indicated experiments following 40-48 h of the recovery.

Western blot analysis. Cells were lysed on ice for $30 \mathrm{~min}$ in a buffer containing $20 \mathrm{mM}$ Tris- $\mathrm{HCl}$ ( $\mathrm{pH} 7.4), 100 \mathrm{mM} \mathrm{NaCl}, 0.5 \%$ NP-40, $0.1 \mathrm{mM} \mathrm{Na}_{3} \mathrm{VO}_{4}, 50 \mathrm{mMNaF}, 30 \mathrm{mM} \mathrm{Na}_{4} \mathrm{O}_{7} \mathrm{P}_{2} \cdot 10 \mathrm{H}_{2} \mathrm{O}$ and a protease inhibitor cocktail (GenDepot, Barker, TX, USA). To compare the levels of secreted MMP-2, cells were cultured for $24 \mathrm{~h}$ in serum-free medium and conditioned media were obtained. Proteins in the lysates or conditioned media were resolved by SDS-PAGE, and transferred to nitrocellulose filters (Millipore, Bedford, MA, USA) using an ECL Semi-Dry Transfer unit (Amersham Life Sciences, Uppsala, Sweden). The nitrocellulose filters were incubated with a blocking buffer (10\% non-fat dry milk and $0.05 \%$ Tween in PBS) for $1 \mathrm{~h}$ and then incubated overnight with primary antibodies at $4^{\circ} \mathrm{C}$. After incubation with secondary antibodies, peroxidase activity was assessed using a chemiluminescence-based detection system (Thermo Fisher Scientific).

Invasion assay. The invasion assay was performed as previously described (21). Briefly, $0.2 \mathrm{ml}$ of transfected cells $\left(1-1.75 \times 10^{5}\right.$ cells $\left./ \mathrm{ml}\right)$ in serum-free medium were seeded onto the upper surfaces of Matrigel-coated polycarbonate filters (BD Biosciences, Bedford, MA, USA) in a modified Boyden chamber (Corning Inc., Corning, NY, USA). The lower compartments of the chambers were filled with $0.6 \mathrm{ml}$ of medium supplemented with $10 \%$ heat-inactivated FBS. After $24 \mathrm{~h}$ of incubation at $37^{\circ} \mathrm{C}$ and $5 \% \mathrm{CO}_{2}$, the cells that had migrated to the lower surface of the filter were fixed, stained using a Diff-Quick kit (Fisher Scientific, Pittsburgh, PA, USA), and counted under a microscope.
PI3K activity assay. The PI3K assay was conducted using a PI3K ELISA kit (Echelon Biosciences, Salt Lake City, UT, USA) according to the manufacturer's protocol. Briefly, cells were lysed with ice-cold lysis buffer (20 mM Tris-HCl, pH 7.4,

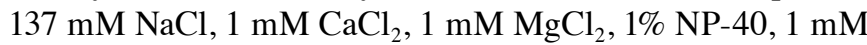
PMSF and $0.1 \mathrm{mM}$ sodium orthovanadate) for $20 \mathrm{~min}$, and the cell lysates were subjected to immunoprecipitation with an anti-PI3K antibody. The immunoprecipitated PI3K was incubated with the PI $(4,5) \mathrm{P} 2$ substrate, and the generated $\mathrm{PI}(3,4,5)$ P3 was assayed by competitive ELISA.

Statistical analysis. All experiments were carried out at least three times to obtain means and standard deviations as shown in the graphs in the figures. Results were analyzed for statistical significance using the Student's t-test. Differences were considered significant at $\mathrm{P}<0.05$.

\section{Results}

Bmall suppresses cancer cell invasion. To determine whether Bmal1 influences cellular invasiveness, we overexpressed Bmal1 in human A549 lung cancer cells (Fig. 1A). This resulted in a dramatic reduction in cellular invasiveness, as analyzed on Matrigel-coated polycarbonate filters (Fig. 1B). Conversely, the siRNA-mediated reduction in endogenous Bmal1 levels (Fig. 1A) promoted cell invasion (Fig. 1C). These findings suggest that Bmall suppresses cancer invasion. These effects were not mimicked by siRNAs against Per3 or ROR $\alpha$ (Fig. 1D), suggesting that this invasion-suppressing activity is not common to all circadian factors.

A549 cells express wild-type p53 (22). Given that this tumor suppressor is mutated in $>50 \%$ of human tumors (23), we next investigated whether Baml1 suppresses the invasiveness of H1299 lung cancer cells, which were used as representative p53-null cells (24). The invasiveness of H1299 cells was also enhanced and suppressed by siRNA-mediated Baml1 knockdown and its overexpression, respectively (Fig. 2A). Therefore, Baml1 appears to suppress lung cancer cell invasion regardless of p53 expression. To determine whether Bmal1 exerts this function in cancer cells from other organs, we examined U251 glioma cells. The invasiveness of these cells was again increased and decreased by Bmall knockdown and overexpression, respectively (Fig. 2B), suggesting that Bmal1 suppresses the invasion of glioma cells. Together, these results suggest that Bmal1 reduces the invasiveness of multiple cancer types in a p53-independent manner.

Bmall suppresses the PI3K-Akt-MMP-2 pathway. The PI3KAkt-MMP-2 pathway is involved in promoting cell invasion under many experimental conditions (25-27). Here, we found that PI3K activity was elevated in Baml1-knockdown cells (Fig. 3A), while no change was evident in the levels of the p85 subunit of PI3K or PTEN, an endogenous inhibitor of PI3K (28) (Fig. 3B). This suggests that Baml1 knockdown induces PI3K activation. Bmal1 knockdown also elevated Akt phosphorylation and MMP-2 protein levels, suggesting that Baml1 may suppress the PI3K-Akt-MMP-2 invasion pathway. To confirm this, cells were treated with the Bamll-targeting siRNAs in the presence or absence of inhibitors for PI3K (LY294002), Akt (Akt inhibitor) and MMP-2 (OA-Hy). As expected, these 
A
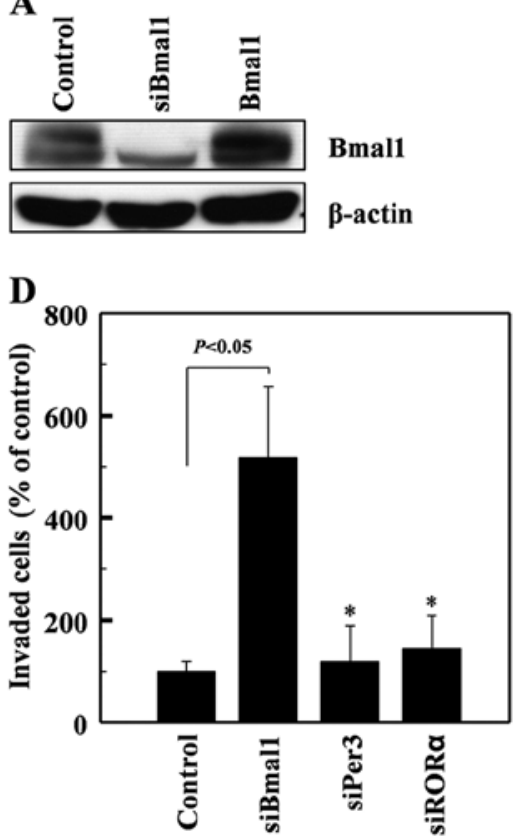

B

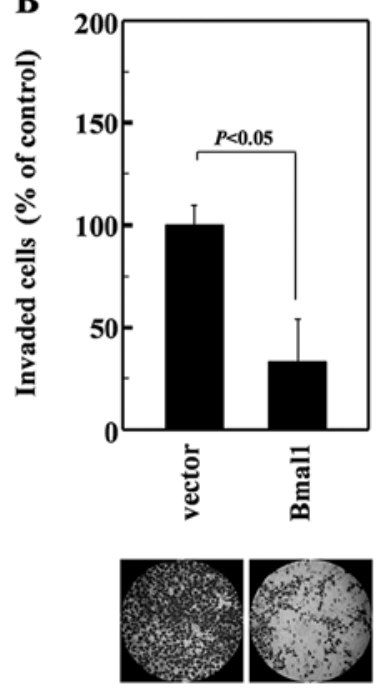

C

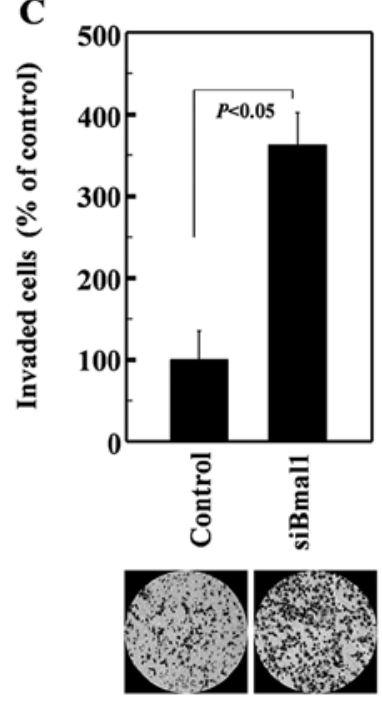

Figure 1. Bmal1 suppresses A549 lung cancer cell invasion. (A) Human A549 lung cancer cells were transfected with the empty (control) or Bmal1-expressing pCMV-SPORT6 vectors. Where indicated, the cells were alternatively treated with Bmal1-targeting siRNAs. After a 46-h incubation, the cellular levels of Bmall were analyzed by western blotting, using $\beta$-actin as a loading control. (B) The invasiveness of control and Bmal1-overexpressing cells was compared using Matrigel-coated membranes. (C) The invasiveness of cells transfected with either control or Bmal1-targeting siRNAs was compared. (D) A549 cells were treated with control siRNAs or those against Bmal1, Per3, or ROR $\alpha$, and cellular invasiveness was compared. The graphs show the means and SD from three independent experiments. ${ }^{*} \mathrm{P}>0.05$ vs. control siRNA.

A

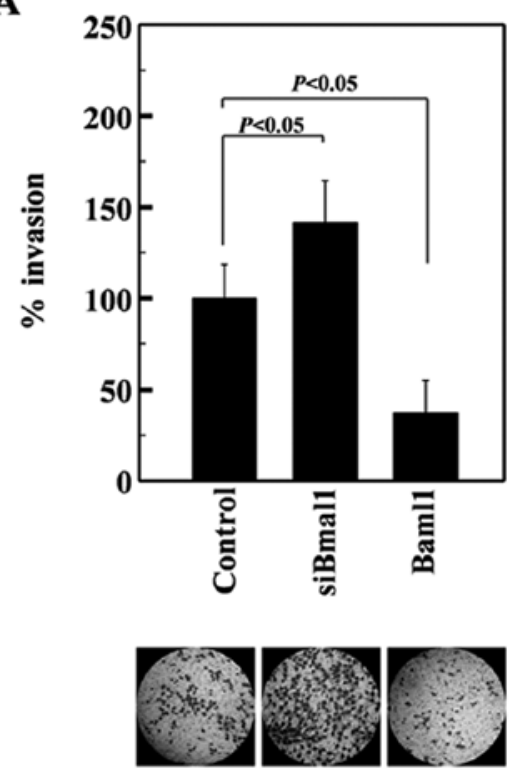

B

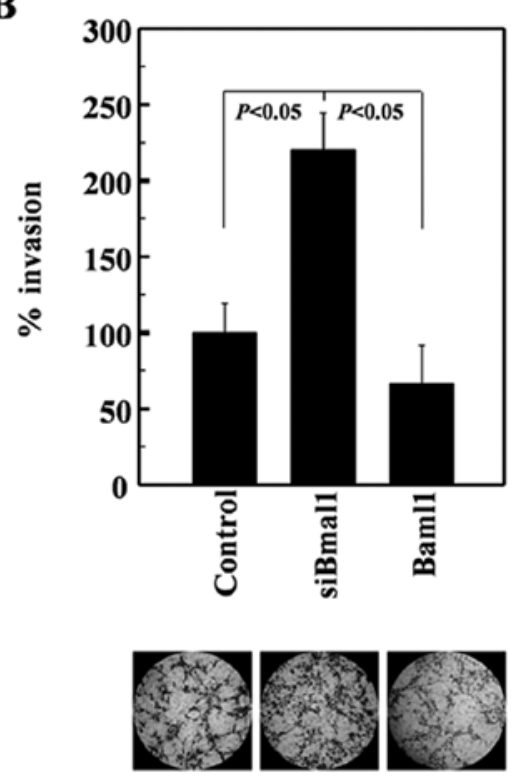

Figure 2. Bmal1 reduces the invasiveness of multiple types of cancer cells. (A) Human H1299 lung cancer and (B) U251 glioma cells were treated with Bmal1targeting siRNAs or Bmall-expressing vectors. After a 46-h incubation, cellular invasiveness was analyzed.

inhibitors attenuated the Bmall siRNA-induced invasion of A549 cells (Fig. 3C), suggesting that Bmall reduces cellular invasiveness by suppressing the PI3K-Akt-MMP-2 pathway.

Bmall antagonizes the invasion-promoting action of Bcl-w. $\mathrm{Bcl}-\mathrm{w}$ is a pro-survival member of the Bcl-2 family of proteins (29), which are upregulated in various types of cancer cells $(30,31)$. Bcl-w protects cells from apoptotic stimuli and also promotes the invasion of cancer cells by activating the PI3K-Akt-MMP-2 pathway $(26,27)$. Therefore, we aimed to ascertain whether Bmal1 antagonizes the invasion-promoting action of Bcl-w. To accomplish this, we co-expressed Bmal1 and Bcl-w in lung cancer cells, and examined MMP-2 levels and cellular invasiveness. As reported previously $(26,27)$, 
A

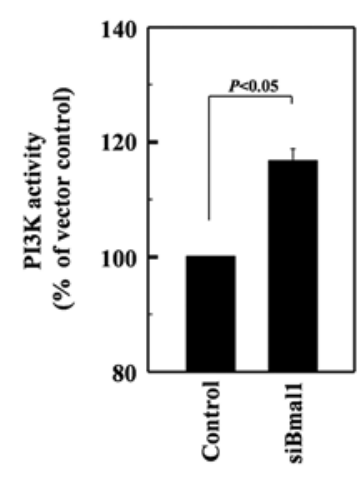

B

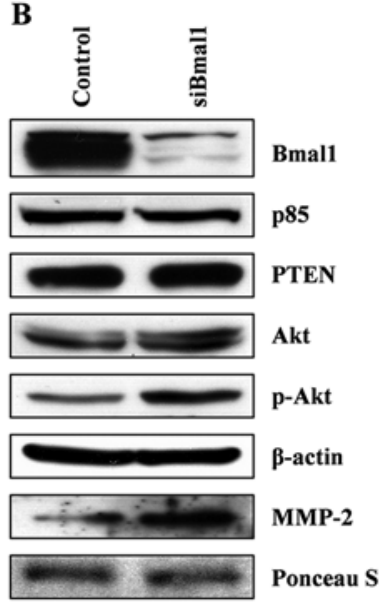

C

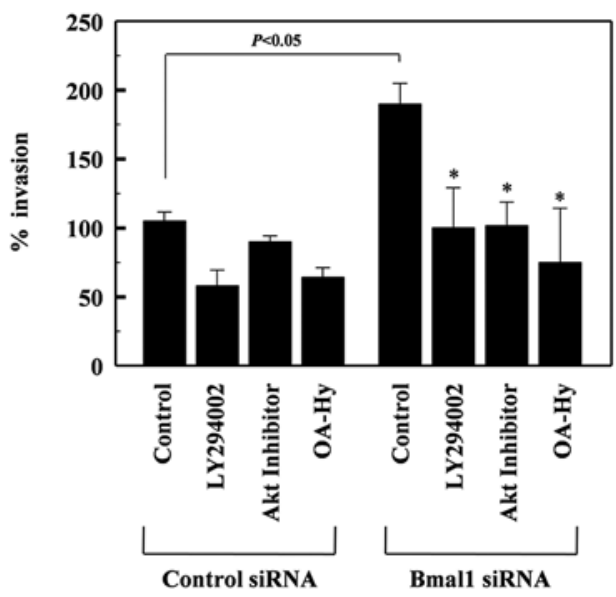

Figure 3. Bmal1 suppresses the PI3K-Akt-MMP-2 pathway. (A) Cell lysates from control or Bmal1-knockdown A549 cells were analyzed for PI3K activity by competitive ELISA. (B) The levels of Bmal1, the p85 subunits of PI3K, PTEN, Akt, phospho-Akt, and $\beta$-actin in the lysates were analyzed by western blotting. Alternatively, conditioned media were prepared using Bmal1-knockdown cells, and MMP-2 levels were analyzed by western blotting. Protein loading was verified by Ponceau S staining. (C) Control and Bmal1-knockdown cells were incubated in the presence or absence of LY294002 (5 $\mu \mathrm{M})$, Akt inhibitor $(5 \mu \mathrm{M})$, or OA-Hy $(10 \mu \mathrm{M})$ for $24 \mathrm{~h}$, and cellular invasiveness was compared. "P<0.05 vs. Bmall siRNA control.

A

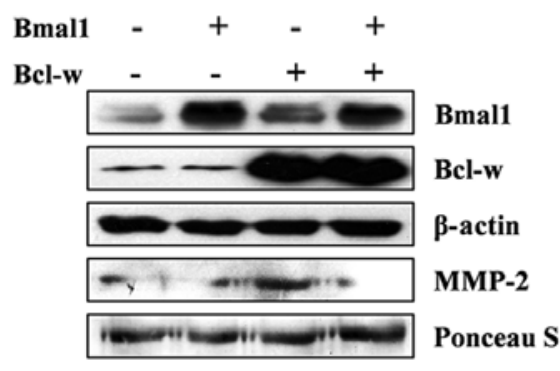

B

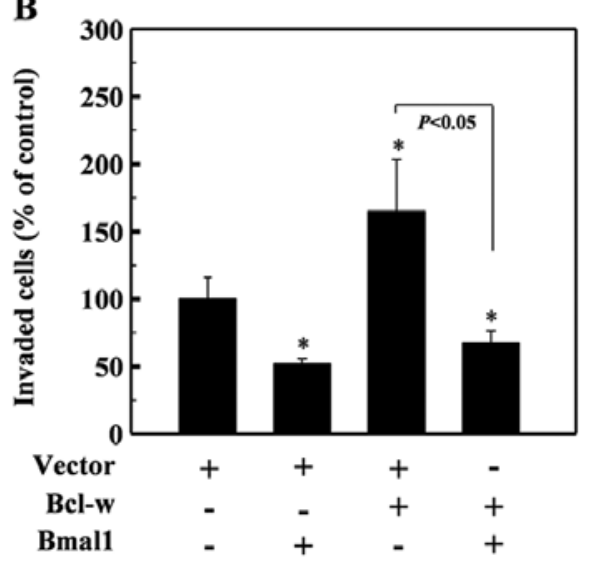

C

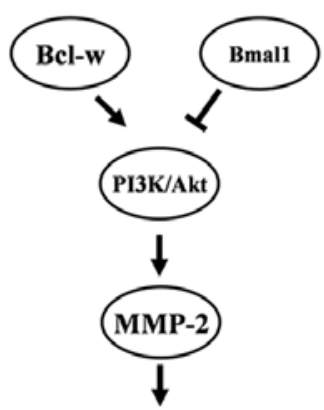

Cancer invasion

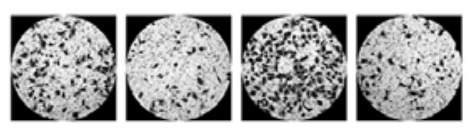

Figure 4. Bmall antagonizes the invasion-promoting action of Bcl-w. (A) H1299 cells were transfected with the indicated combinations of Bmal1- and Bcl-wexpressing vectors. After a 46-h incubation, cell lysates and conditioned media were prepared, and the levels of the indicated proteins were analyzed by western blotting. (B) The invasiveness of the transfectants was compared. " $\mathrm{P}<0.05$ vs. vector control. (C) Schematic model of the suppression of cellular invasiveness by Bmal1, via blockage of the PI3K-Akt-MMP-2 pathway. This contrasts with the ability of Bcl-w to promote cell invasion by activating the PI3K-Akt-MMP-2 pathway. Given that Bmall antagonizes Bcl-w-induced invasion, we speculate that Bmal1 and Bcl-w may compete to reciprocally regulate invasion.

Bcl-w overexpression enhanced the levels of MMP-2 (Fig. 4A) and cellular invasiveness (Fig. 4B). However, both of these events were abolished by the co-expression of Bmal1 (Fig. 4A and $\mathrm{B}$ ), suggesting that Bmall acts against Bcl-w to reduce cellular invasiveness.

\section{Discussion}

In the present study, we demonstrated that Bmall suppresses cancer cell invasion. This was demonstrated by both Bmall overexpression and RNA interference experiments. This effect of Bmall was observed in lung cancer and glioma cells, indicating that Bmall reduces the invasiveness of multiple types of cancer.
We believe that Bmall exerts this function by suppressing the invasion pathway that involves PI3K, Akt and MMP-2. This was initially suggested by the observation that Bmal1 knockdown increased the levels of PI3K activity, Akt phosphorylation, and MMP-2 protein, and was further confirmed by our observation that Bmall knockdown-induced cell invasion was blocked by inhibitors of PI3K, Akt, and MMP-2. Although certain circadian factors have been reported to regulate tumor growth and resistance (32), this is the first report that such a factor can also regulate cancer cell invasiveness.

Previous studies have shown that Bmall is downregulated in certain types of cancer (33) and suppresses tumor growth in cell culture and animal models (20). Together, these reports 
and our present results suggest that Bmall functions as a tumor suppressor. This view is further supported by our finding that Baml1 acts against the oncogene, Bcl-w, to prevent MMP-2 accumulation and cell invasion. As Bcl-w activates the PI3KAkt-MMP-2 pathway, we propose that Bmall and Bcl-w may reciprocally regulate this invasion pathway (Fig. 4C).

The theory that Bmall acts as a tumor suppressor led us to examine the possible relationship between Bmall and p53, a well-characterized tumor suppressor that also suppresses cancer cell invasion (34). However, we found that knockdown of Bmal1 elevates the invasiveness of p53-expressing and p53-null lung cancer cells to almost equal extents. Therefore, Bmall appears to act as a tumor suppressor via a p53-independent mechanism, at least for the regulation of cellular invasiveness.

In conclusion, we showed that Bmall attenuates cancer cell invasion by suppressing the PI3K-Akt-MMP-2 pathway. This result supports the notion that there is a tight molecular link between circadian rhythms and tumor formation/progression.

\section{Acknowledgements}

This study was supported by a grant from the Nuclear Research and Development Program of the National Research Foundation of Korea (NRF) funded by the Korean Government (MEST) (2012M2A2A7010459), and in part by the Basic Science Research Program through the NRF (2012-0000482).

\section{References}

1. Friedl P and Alexander S: Cancer invasion and the microenvironment: plasticity and reciprocity. Cell 147: 992-1009, 2011.

2. Mohawk JA, Green CB and Takahashi JS: Central and peripheral circadian clocks in mammals. Annu Rev Neurosci 35: 445-462, 2012.

3. Takahashi JS, Hong HK, Ko CH and McDearmon EL: The genetics of mammalian circadian order and disorder: implications for physiology and disease. Nat Rev Genet 9: 764-775, 2008.

4. Rafnsson V, Tulinius H, Jónasson JG and Hrafnkelsson J: Risk of breast cancer in female flight attendants: a population-based study (Iceland). Cancer Causes Control 12: 95-101, 2001.

5. Viswanathan AN, Hankinson SE and Schernhammer ES: Night shift work and the risk of endometrial cancer. Cancer Res 67: 10618-10622, 2007.

6. Schernhammer ES, Kroenke $\mathrm{CH}$, Laden F and Hankinson SE: Night work and risk of breast cancer. Epidemiology 17: 108-111, 2006.

7. Fu L and Lee CC: The circadian clock: pacemaker and tumour suppressor. Nat Rev Cancer 3: 350-361, 2003.

8. Dunlap JC: Molecular bases for circadian clocks. Cell 96: 271-290, 1999.

9. Preitner N, Damiola F, Lopez-Molina L, Zakany J, Duboule D, Albrecht $U$ and Schibler $U$ : The orphan nuclear receptor REV-ERBalpha controls circadian transcription within the positive limb of the mammalian circadian oscillator. Cell 110: 251-260, 2002

10. Sato TK, Panda S, Miraglia LJ, Reyes TM, Rudic RD, McNamara P, Naik KA, FitzGerald GA, Kay SA and Hogenesch JB: A functional genomics strategy reveals Rora as a component of the mammalian circadian clock. Neuron 43: 527-537, 2004.

11. Gery S, Gombart AF, Yi WS, Koeffler C, Hofmann WK and Koeffler HP: Transcription profiling of C/EBP targets identifies Per2 as a gene implicated in myeloid leukemia. Blood 106: 2827-2836, 2005.

12. Winter SL, Bosnoyan-Collins L, Pinnaduwage D and Andrulis IL: Expression of the circadian clock genes Perl and Per2 in sporadic and familial breast tumors. Neoplasia 9: 797-800, 2007.

13. Yeh KT, Yang MY, Liu TC, Chen JC, Chan WL, Lin SF and Chang JG: Abnormal expression of period 1 (PER1) in endometrial carcinoma. J Pathol 206: 111-120, 2005.
14. Pogue-Geile KL, Lyons-Weiler J and Whitcomb DC: Molecular overlap of fly circadian rhythms and human pancreatic cancer. Cancer Lett 243: 55-57, 2006.

15. Fu L, Pelicano H, Liu J, Huang $P$ and Lee C: The circadian gene period 2 plays an important role in tumor suppression and DNA damage response in vivo. Cell 111: 41-50, 2002.

16. Gery S, Komatsu N, Baldjyan L, Yu A, Koo D and Koeffler HP: The circadian gene per1 plays an important role in cell growth and DNA damage control in human cancer cells. Mol Cell 22: 375-382, 2006.

17. Hua H, Wang Y, Wan C, Liu Y, Zhu B, Wang X, Wang Z and Ding JM: Inhibition of tumorigenesis by intratumoral delivery of the circadian gene mPer 2 in C57BL/6 mice. Cancer Gene Ther 14: 815-818, 2007.

18. Oda A, Katayose Y, Yabuuchi S, Yamamoto K, Mizuma M, Shirasou S, Onogawa T, Ohtsuka H, Yoshida H, Hayashi H, Rikiyama T, Kim H, Choe Y, Kim K, Son H, Motoi F, Egawa S and Unno M: Clock gene mouse period2 overexpression inhibits growth of human pancreatic cancer cells and has synergistic effect with cisplatin. Anticancer Res 29: 1201-1209, 2009.

19. King DP, Zhao Y, Sangoram AM, Wilsbacher LD, Tanaka M, Antoch MP, Steeves TD, Vitaterna MH, Kornhauser JM, Lowrey PL, Turek FW and Takahashi JS: Positional cloning of the mouse circadian clock gene. Cell 89: 641-653, 1997.

20. Zeng ZL, Wu MW, Sun J, Sun YL, Cai YC, Huang YJ and Xian LJ: Effects of the biological clock gene Bmall on tumour growth and anti-cancer drug activity. J Biochem 148: 319-326, 2010.

21. Kim EM, Kim J, Park JK, Hwang SG, Kim WJ, Lee WJ, Kang SW and Um HD: Bcl-w promotes cell invasion by blocking the invasion-suppressing action of Bax. Cell Signal 24: 1163-1172, 2012.

22. Lehman TA, Bennett WP, Metcalf RA, Welsh JA, Ecker J, Modali RV, Ullrich S, Romano JW, Appella E, Testa JR, Gerwin BI and Harris CC: p53 mutations, ras mutations, and p53-heat shock 70 protein complexes in human lung carcinoma cell lines. Cancer Res 51: 4090-4096, 1991.

23. Soussi T, Dehouche K and Béroud C: p53 website and analysis of p53 gene mutations in human cancer: forging a link between epidemiology and carcinogenesis. Hum Mutat 15: 105-113, 2000.

24. Roberson RS, Kussick SJ, Vallieres E, Chen SY and Wu DY: Escape from therapy-induced accelerated cellular senescence in p53-null lung cancer cells and in human lung cancers. Cancer Res 65: 2795-2803, 2005.

25. Shukla S, Maclennan GT, Hartman DJ, Fu P, Resnick MI and Gupta S: Activation of PI3K-Akt signaling pathway promotes prostate cancer cell invasion. Int J Cancer 121: 1424-1432, 2007.

26. Bae IH, Park MJ, Yoon SH, Kang SW, Lee SS, Choi KM and Um HD: Bcl-w promotes gastric cancer cell invasion by inducing matrix metalloproteinase-2 expression via phosphoinositide 3-kinase, Akt, and Sp1. Cancer Res 66: 4991-4995, 2006.

27. Bae IH, Yoon SH, Lee SB, Park JK, Ho JN and Um HD: Signaling components involved in Bcl-w-induced migration of gastric cancer cells. Cancer Lett 277: 22-28, 2008.

28. Kong D and Yamori T: Advances in development of phosphatidylinositol 3-kinase inhibitors. Curr Med Chem 16: 2839-2854, 2009.

29. Cory S and Adams JM: The Bcl-2 family: regulators of the cellular life-or-death switch. Nat Rev Cancer 2: 647-656, 2002.

30. Lee HW, Lee SS, Lee SJ and Um HD: Bcl-w is expressed in a majority of infiltrative gastric adenocarcinomas and suppresses the cancer cell death by blocking stress-activated protein kinase/c-Jun NH2-terminal kinase activation. Cancer Res 63: 1093-1100, 2003.

31. Hoelzinger DB, Mariani L, Weis J, Woyke T, Berens TJ, McDonough WS, Sloan A, Coons SW and Berens ME: Gene expression profile of glioblastoma multiforme invasive phenotype points to new therapeutic targets. Neoplasia 7: 7-16, 2005

32. Chen-Goodspeed $M$ and Lee CC: Tumor suppression and circadian function. J Biol Rhythms 22: 291-298, 2007.

33. Mazzoccoli G, Panza A, Valvano MR, Palumbo O, Carella M, Pazienza V, Biscaglia G, Tavano F, Di Sebastiano P, Andriulli A and Piepoli A: Clock gene expression levels and relationship with clinical and pathological features in colorectal cancer patients. Chronobiol Int 28: 841-851, 2011.

34. Muller PA, Vousden KH and Norman JC: p53 and its mutants in tumor cell migration and invasion. J Cell Biol 192: 209-218, 2011. 